\title{
A new feature of importance for the TNF-alpha system in inflammation-Bilateral myositis that develops early in response to unilateral overuse shows a marked involvement of TNF-alpha not only in the exercised side but also contralaterally*
}

\author{
Lina Renström", Per Stål, Sture Forsgren \\ Department of Integrative Medical Biology, Anatomy Section, Umeå University, Umeå, Sweden; \\ "Corresponding Author: lina.renstrom@umu.se
}

Received 18 October 2013; revised 12 November 2013; accepted 19 November 2013

Copyright (C) 2013 Lina Renström et al. This is an open access article distributed under the Creative Commons Attribution License, which permits unrestricted use, distribution, and reproduction in any medium, provided the original work is properly cited.

\section{ABSTRACT}

Using a rabbit model leading to myositis in response to exercise-induced muscle overuse, we have previously observed that TNF-alpha is involved in the exercised muscle in early developing myositis as well as both ipsi- and contralaterally in the myositis which develops in response to a lengthened period of overuse. It is unknown if TNF-alpha can also be engaged contralaterally in early stages of myositis. The hypothesis was that this is the case. It was therefore evaluated whether the TNF-alpha system is early involved contralaterally. An experimental model of 1 week of overuse of the soleus muscle on one side leading to myositis was used, and in situ hybridization and immunohistochemistry were applied to study the expression patterns of TNF-alpha in the soleus muscle in the contralateral side. TNF-alpha was expressed in the myositis process which occurred contralaterally. There were thus TNF-alpha mRNA reactions in the cells of the inflammatory infiltrates, in blood vessel walls and in certain of the muscle fibers. Parts of the latter were necrotic fibers, whereas others were interpreted to be in a regenerative stage. TNF-alpha immunoreactions were seen for infiltrating white blood cells. The observations show that the TNF-alpha system is

\footnotetext{
*Financial support has been obtained from the Faculty of Medicine, Umeå University, and the J.C. Kempe and Seth M. Kempe Memorial Foundations, Örnsköldsvik.

There are no conflicts of interest.
}

early involved in the cross-over effects that occur in response to unilateral muscle overuse leading to myositis bilaterally. TNF-alpha is likely to have pro-inflammatory and destructive effects but also to have effects in the muscle regenerative processes. The occurrence of an early involvement of the TNF-alpha system contralaterally to the injury side shows a new aspect of importance of this system in inflammation.

Keywords: TNF-Alpha; Muscle Overuse; Myositis; Soleus Muscle; Contralateral

\section{INTRODUCTION}

TNF-alpha is a well-known pro-inflammatory cytokine [1]. It is thus produced in the infiltrating inflammatory cells in the process of inflammation [2-5]. However, TNF-alpha is also considered to be involved in tissue repair and differentiation [6,7].

Myositis is a marked inflammation of a muscle leading to muscle weakness and pain. Myositis can be related to processes of an autoimmune character, which is the situation in inflammatory myopathies such as polymyositis, inclusion body myositis and dermatomyositis [8]. Myositis can also occur in response to marked overuse or muscle injury $[9,10]$. It is previously described that TNFalpha can be involved in myositis [11], and it actually can play a role in the pathogenesis of the myositis which occurs in inflammatory myopathies $[12,13]$. It is reported that TNF-alpha immunoreactions are detectable in the inflammatory cells in the myositis process in cases of inflammatory myopathies [14,15] and in such cells in 
murine skeletal muscle in response to experimental crushinjury [16]. TNF-alpha expression has also been noted for injured muscle fibers and connective tissue cells in these occasions [14-16].

There exists no animal model where the importance of the TNF-alpha system for myositis can be evaluated. We have, however, developed a model in rabbits where this process can be followed. In this exercise-induced overuse model, myositis was found to occur for the triceps surae muscle [17]. By using this model, we have observed that TNF-alpha was expressed in infiltrating white blood cells, as well as in blood vessel walls, especially after prolonged treatment periods (up to 6 weeks) [18]. Interestingly, TNF-alpha mRNA reactions were detected in necrotic muscle fibers as well as in fibers which were in a phase of regeneration [18]. By using this experimental model, in combination with treatments with injections having a pro-inflammatory outcome, there was a development of a myositis process already after 1 week of experiment $[19,20]$. Using this modification of the model, we found that there is an expression of TNF-alpha in infiltrating white blood cells and in some muscle fibers in areas exhibiting the inflammatory infiltrates already at this stage [20]. In these studies on the TNF-alpha system, the soleus muscle part of the triceps surae muscle of the experimental side was evaluated [18,20].

In our continuing studies using the overuse rabbit model, we have unexpectedly noted that there was a marked myositis and muscle derangement process not only in the experimental side but also in the contralateral non-exercised side [17]. In our previous evaluation of the TNFalpha system during prolonged periods of overuse, we observed that TNF-alpha was expressed in the infiltrating white blood cells, blood vessel walls and also necrotic/ regenerating muscle fibers contralaterally [18]. These findings suggest that the TNF-alpha system is involved in both the ipsilateral and contralateral sides in response to prolonged unilateral muscle overuse. Such a bilateral involvement of the TNF-alpha system in response to a unilateral muscle injury/inflammation has not previously been shown. The occurrence of a contralateral involvement of the TNF-alpha system can be related to a late phase in the myositis process in the contralateral side, this involvement being secondary to other features in the development of the bilateral involvement of the muscles. However, the contralateral involvement of the TNF-alpha system can also be an early manifestation in the bilateral myositis processes. It is not known if this is the case.

In the present study we have taken advantage of the existence of the modification of the overuse muscle model described above, leading to early myositis, in studies on the importance of the TNF-alpha system in the contralateral side in the early processes of myositis. The muscle overuse was thus combined with local injections of sub- stances having pro-inflammatory effects. The aim was to evaluate whether the TNF-alpha system is also early activated in the myositis process in the contralateral side in response to unilateral experiments. In situ hybridization and immunohistochemistry were applied. The hypothesis was that the TNF-alpha system has an important role in the development of the myositis in the contralateral muscles already at an early stage.

\section{MATERIAL AND METHODS}

\subsection{Animals}

The experiments were carried out on female, 6 - 9 months old New Zealand white rabbits with a weight of approximately $4 \mathrm{~kg}$. In total, muscle samples from 17 animals were evaluated in the present study. Six of the animals belonged to a reference group without any exercise (the control group). The other 11 animals were exposed to an exercise procedure for the right triceps surae muscle, with additional local injections of substances having pro-inflammatory effects (c.f. below). The animals were kept in ordinary cages allowing good freedom of movement in-between the experimental sessions.

\subsection{Exercise Procedure}

The exercise protocol conforms to that previously used in our laboratory [17-21]. That includes the use of a "kicking machine" whereby repetitive passive flexionextension of the right ankle was achieved by means of a pneumatic piston. During the plantar flexion phase, an active contraction was furthermore induced by electrical stimulation via surface electrodes (Pediatric electrodes 40,426 A, Hewlett Packard). An impulse of 0.2 ms duration was delivered $85 \mathrm{~ms}$ after the initiation of the plantar flexion at an amplitude of $35-50 \mathrm{~V}$. The movement frequency was 150 movements per minute. This exercise session lasted for 2 hours and was repeated every second day for one week. The left leg was not attached to the kicking machine and the pelvis was strapped down.

During the experiment, the animals were kept under anaesthesia by i.m. injection of fentanylfluanison (0.2 $0.3 \mathrm{ml} / \mathrm{kg})$ and diazepam $(0.2 \mathrm{ml} / \mathrm{kg})$. Fentanylfluanison $(0.1 \mathrm{ml} / \mathrm{kg})$ was injected each $30-45 \mathrm{~min}$ in order to maintain anaesthesia. For analgesia, buprenorphine $(0.03$ $\mathrm{mg} / \mathrm{kg} \mathrm{s.c.)} \mathrm{was} \mathrm{given} \mathrm{after} \mathrm{each} \mathrm{experiment} \mathrm{session.} \mathrm{For}$ further details about the apparatus and the exercise protocol see $[19,20,22,23]$.

\subsection{Injection Treatments}

Injection treatments were, in accordance with previous descriptions $[19,20]$, given in the peritendinous tissue of the Achilles tendon of the exercised (right) side. The following substances were injected: Substance P (SP) $\left(10^{-8}\right.$ 
$\mu \mathrm{mol} / \mathrm{mL}$ ), Captopril (C) (Sigma) (c4042, $30 \mu \mathrm{mol} / \mathrm{kg}$ ), both in distilled water (volume $1 \mathrm{ml}$ ) and DL-Thiorphan (Th) (Sigma) $(500 \mu \mathrm{g} / \mathrm{ml}, 0.02 \mathrm{ml})$. The injections of Captopril and DL-Thiorphan were made in order to inhibit the activity of angiotensin-converting enzyme and to diminish endopeptidase activity respectively. Six animals were injected with only $\mathrm{C}$ (the $\mathrm{C}$ group) and five with a combination of $\mathrm{SP}+\mathrm{C}+\mathrm{Th}$ (the $\mathrm{SP}+\mathrm{C}+\mathrm{Th}$ group).

\subsection{Sampling, Fixation and Sectioning}

On the day after the last exercise, the rabbits were sacrificed by an overdose of Pentobarbital and tissue was collected. Muscle samples conforming to the soleus part of the triceps surae muscle $(5-8 \times 10 \mathrm{~mm})$ of the left leg (non-experimental side) were further processed.

The samples were fixed overnight at $4^{\circ} \mathrm{C}$ in $4 \%$ formaldehyde in $0.1 \mathrm{M}$ phosphate buffer $(\mathrm{pH} 7.0)$ and washed in Tyrode's solution containing $10 \%$ sucrose at $4^{\circ} \mathrm{C}$ overnight, followed by mounting on a cardboard in OCT embedding medium (TissueTek ${ }^{\circledR}$, Miles Laboratories, Naperville, Ill, USA). Thereafter the samples were frozen in liquid propane chilled with liquid nitrogen, and stored at $-80^{\circ} \mathrm{C}$. The samples used for staining for morphology and for immunohistochemistry were cut in sections with a thickness of $5-8 \mu \mathrm{m}$ using a cryostat and were mounted on chrome-alum gelatine precoated slides and processed for morphology (Htx-Eosin staining) or immunohistochemistry. $10 \mu \mathrm{m}$ thick sections were cut for the purpose of being used for in situ hybridization (c.f. below).

\subsection{Processing for in Situ Hybridization}

A digoxigenin (DIG)-hyperlabeled oligonucleotide probe (ssDNA) (GD1001-DS custom designed; GeneDetect, New Zealand) for detection of rabbit TNF-alpha mRNA was used. The antisense sequence of the probe was CGGCGAAGCGGCTGACAGTGTGAGTGAGGAGCACGTAGGAGCGGCAGC. The procedures were performed according to an established protocol [24], using an alkaline phosphatase-labeled anti-DIG antibody for detection $[19,20,25,26]$. The probe for TNF-alpha mRNA was used at $50 \mathrm{ng}$ in $15 \mu \mathrm{l}$ of hybridization solution.

Tissue specimens corresponding to 7 specimens of the experimental animals (five from the $\mathrm{C}$-group and 2 from the $\mathrm{SP}+\mathrm{C}+\mathrm{Th}$ group) and 2 specimens from the control group were processed. Sections were cut into $10 \mu \mathrm{m}$ thick fresh cryosections using a cryostat (with a knife washed in $70 \% \mathrm{EtOH}$ in DEPC- $\mathrm{H}_{2} \mathrm{O}$ ) and mounted onto Super Frost Plus slides (nr.041200, Menzel Gläser). The protocol that thereafter followed was that previously used in our laboratory for detection of mRNA for various sub- stances [19,20,25,26].

An alkaline phosphatase (AP)-labeled anti-DIG antibody (Roche, Germany, 11,093,274,910) was used for detection. The sections were finally mounted in Pertex mounting medium. The corresponding sense DIG-hyperlabeled ssDNA probe was used as a negative control. As a positive control probe, a $\beta$-actin antisense probe (GD5000-OP) was used, comparisons being made with a sense $\beta$-actin probe (GeneDetect, New Zealand).

\subsection{Immunohistochemistry}

Tissue sections from specimens of all animals in the various groups were stained immunohistochemically for demonstration of TNF-alpha. The immunostaining procedures were the same as those that were previously used for demonstration of TNF-alpha immunostaining [18,20]. As normal serum, 5\% normal donkey serum (code no: 017-000-121, Jackson Immune Research Lab. Inc.) was used. As secondary antiserum two variants were used: FITC-conjugated AffiniPure donkey antigoat IgG (Jackson ImmunoResearch Lab Inc., dilution 1:100) or Alexa FluorO 488 donkey antigoat (Invitrogen, dilution 1:300).

\subsection{TNF-Alpha Antibody and Control Stainings}

An antibody against TNF-alpha produced in goats was used (AF-210-NA; R \& D Systems, dilution used 1:50). This antibody is, according to the supplier, directed against E. coli-derived recombinant human TNF-alpha. The TNF-alpha specific IgG was purified by human TNF-alpha affinity chromatography and is specific via having the ability to neutralize the biological activity of recombinant human TNF-alpha. Of note, the TNF-alpha amino acid sequence homology between species is reported to be highly conserved and TNF-alpha DNA sequence comparison shows that there is an overall high sequence homology between various species (including rabbit) [27].

Control stainings conformed to stainings when the primary antibody was omitted. Preabsorption of the primary antibody with TNF-alpha antigen has been previously performed, showing that reactions obtained in rabbit muscle tissue were abolished via this procedure [20].

\section{RESULTS}

\subsection{Morphology}

In both the $\mathrm{C}$ and the $\mathrm{SP}+\mathrm{C}+\mathrm{Th}$ groups, pronounced white blood cell infiltration (myositis) and an overall occurrence of various histopathological muscle changes were observed in parts of the muscle specimens (Figure 


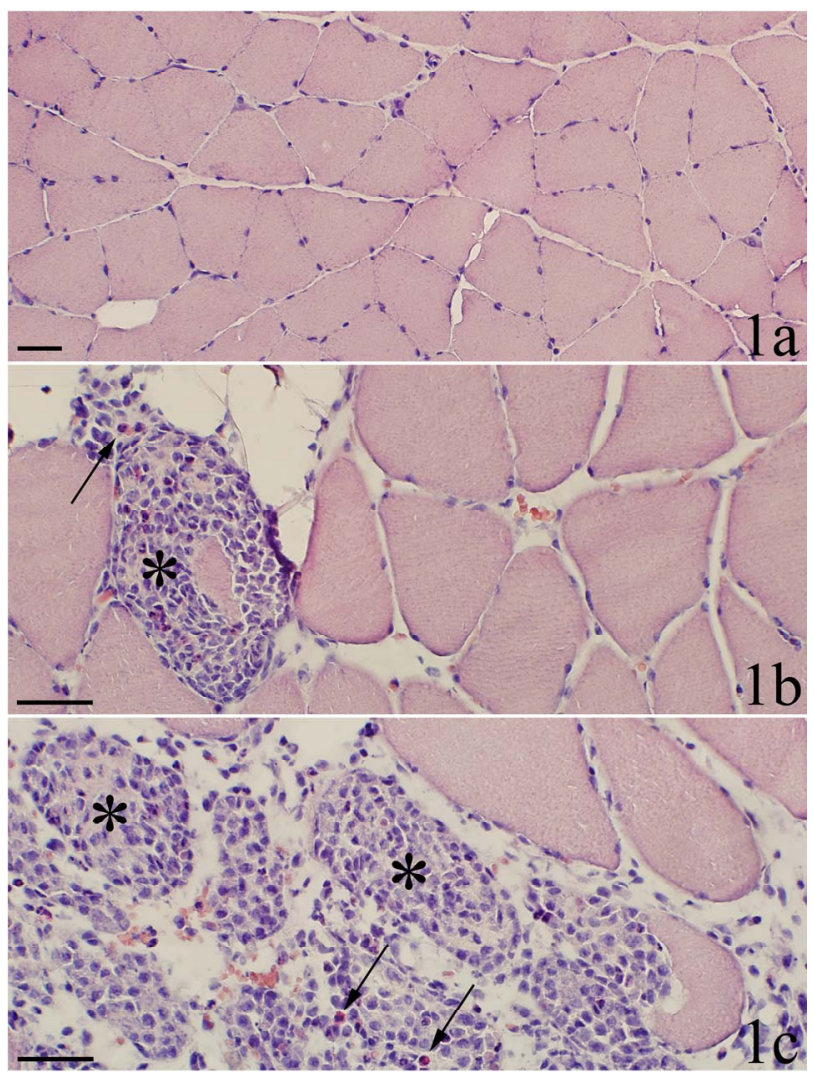

Figure 1. H \& E. a Control sample. It shows normal soleus muscle tissue. $\mathrm{b}$ and $\mathrm{c}$ are from myositis sample ( $\mathrm{SP}+\mathrm{C}+\mathrm{Th}$ group). In $\mathrm{b}$, one muscle fiber is seen to be almost completely infiltrated by white blood cells, i.e. representing a necrotic fiber (asterisk). In c, a massive infiltration of cells into the muscle tissue is seen. Normally-appearing muscle fibers to the upper right. The morphological appearance favours that the grouping of cells that is seen represents grouping of cells within previously existing muscle fibers (asterisks). Some of the cells are scattered. Note that a few of the infiltrating cells are reddish, i.e. eosinophils (arrows) a fact which also is seen in the necrotic fiber in b. Scale bars $=50 \mu \mathrm{m}$.

1). Occurrence of abnormally appearing muscle fibers was a noteworthy feature. A large number of these muscle fibers were infiltrated by white blood cells, some of the fibers being completely filled with such cells (Figures $\mathbf{1 b}$ and $\mathbf{c})$. These muscle fibers can be considered to be necrotic muscle fibers. In areas with severe myositis, the tissue sometimes contained large clusters of another variant of abnormally appearing muscle fibers, namely small sized fibers, which were surrounded by a high amount of loose connective tissue (Figure 2a). All these observations were in principle similar to those noted for the ipsilateral soleus muscle using the present experimental approach $[18,20]$. No morphological changes were observed in the control group.

As the morphological appearances in principle were the same in the C and SP + C + Th groups, these are further on grouped together, termed "myositis animals".
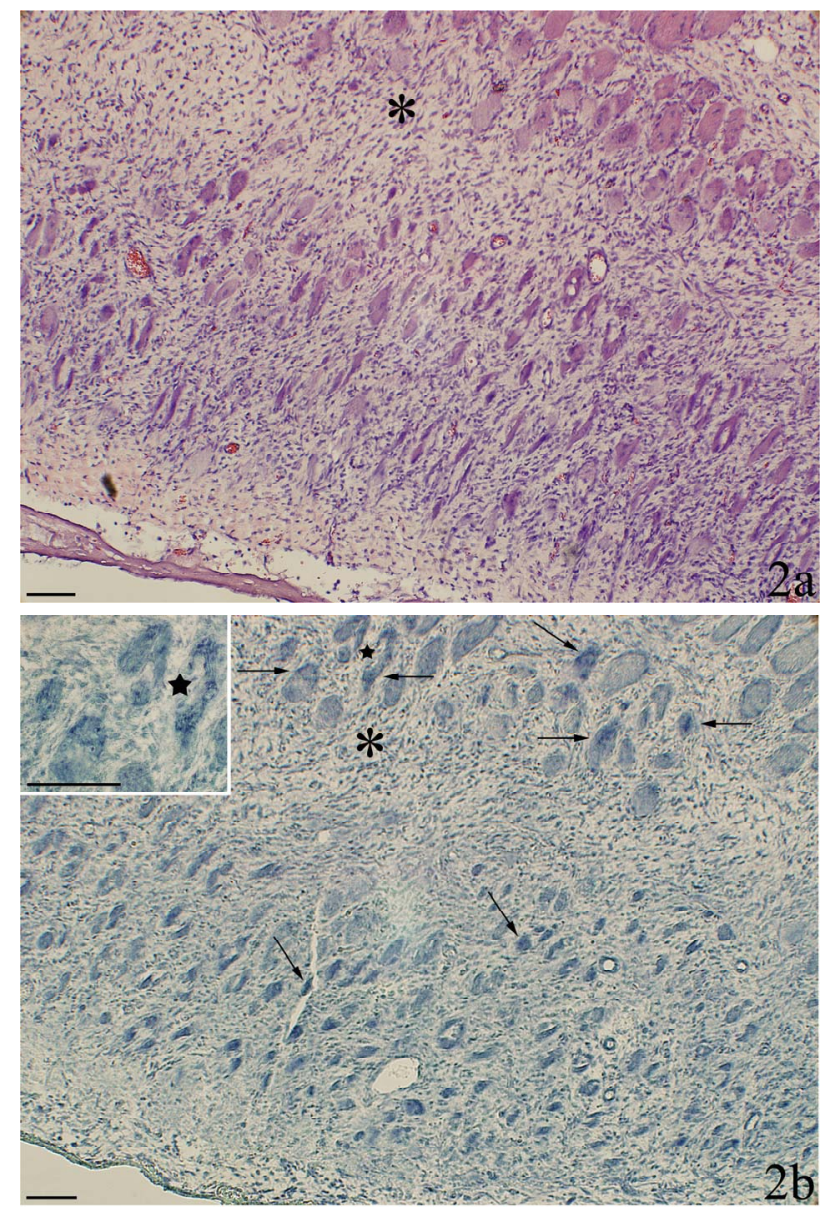

Figure 2. Sample showing myositis from an animal in the $\mathrm{C}$ group. The section in a is stained with $\mathrm{H} \& \mathrm{E}$ and the section in $\mathrm{b}$ is processed with antisense probe for detection of TNF-alpha mRNA (asterisks at similar regions). There is a lot of infiltrated cells in the connective tissue. Most of the muscle fibers are very small and are surrounded by connective tissue. In b, TNF-alpha mRNA reactions, in the form of black granular reactions, are seen in several of the muscle fibers (arrows). An area is shown in larger magnification in inset (star at corresponding muscle fibers). Scale bars $=100 \mu \mathrm{m}$.

\subsection{In Situ Hybridization}

TNF-alpha mRNA reactions were noted for certain of the muscle fibers in the samples of the myositis animals. That included several of those small fibers that were located in association with loose connective tissue (Figure 2b). TNF-alpha mRNA reactions were not seen in the musculature of the control animals nor in areas with normal morphology of myositis animals. Further aspects of muscle fiber reactions are described below.

The walls of some of the blood vessels showed TNFalpha mRNA reactions (Figure 3a). In sections stained with sense probe only unspecific background reactions were visible (Figure $\mathbf{3 b}$ ). Blood vessel reactions were more clearly seen in myositis animals than in the controls and were localized to regions where the inflammatory 
infiltrates dominated. TNF-alpha mRNA reactions were also seen for fibroblasts (Figure 4a), in this case both for myositis and control animals. The occurrence of specific reactions in fibroblasts was verified via comparisons with reaction patterns seen after processing with sense probe (Figure 4b). TNF-alpha mRNA reactions were not seen for nerve fascicles (not shown).

A large part of the white blood cells lying scattered in the connective tissue in the specimens of myositis animals were seen to express TNF-alpha mRNA reactions (Figures 5a and $\mathbf{b}$ ). There was thus a very marked difference in the reaction pattern for the cells when comparing sections processed with antisense and sense probes (Figures $\mathbf{5 b}$ and $\mathbf{c}$ ).

As described above, TNF-alpha mRNA reactions were seen within some of the muscle fibers in areas with marked muscle inflammation. The reactive fibers were

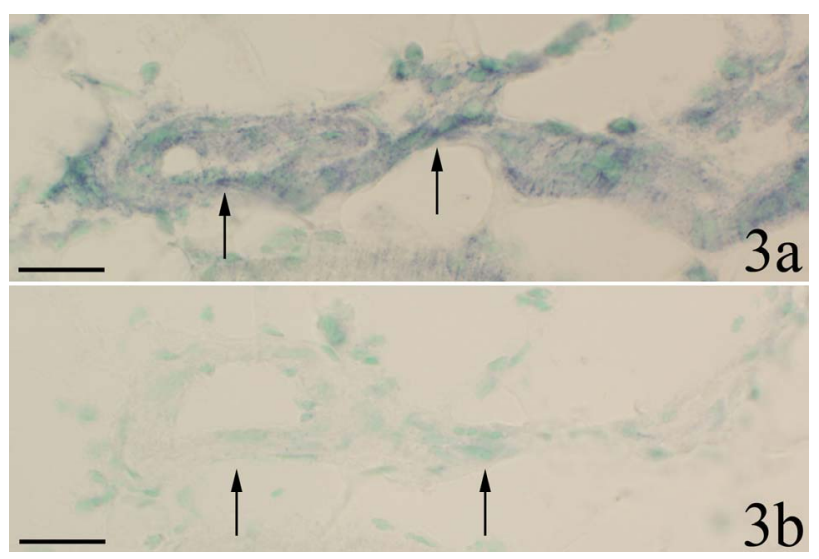

Figure 3. Parallel sections processed with antisense probe for detection of TNF-alpha mRNA in a and with corresponding sense probe in $\mathrm{b}$. Myositis muscle ( $\mathrm{SP}+\mathrm{C}+\mathrm{Th}$ group). There are reactions in the walls of fine blood vessels in a but not in $\mathrm{b}$. Arrows indicate vessel walls. Scale bars: $25 \mu \mathrm{m}$.

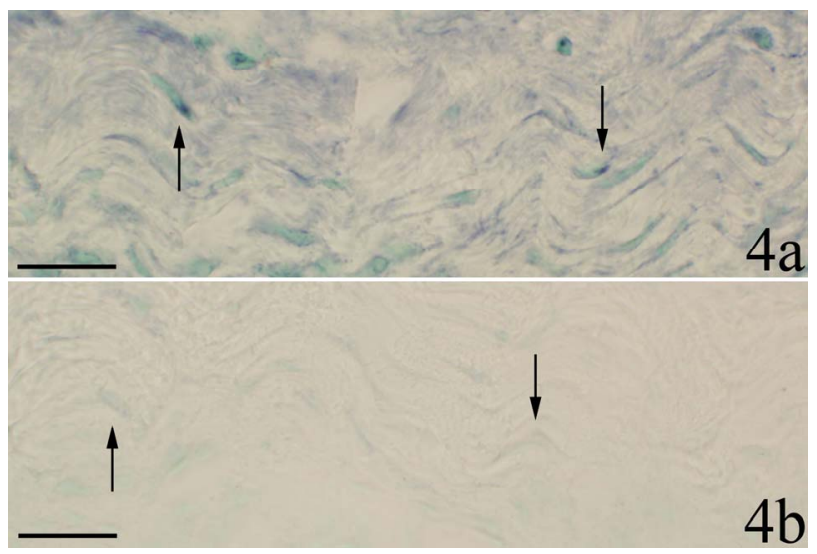

Figure 4. Sections processed for demonstration of TNF-alpha mRNA; antisense staining in a and sense staining in $b$. A region of the soleus muscle composed of connective tissue is shown ( $\mathrm{SP}+\mathrm{C}+\mathrm{Th}$ group). There are reactions in fibroblasts in a but not in b. Arrows indicate fibroblasts. Scale bars $=25 \mu \mathrm{m}$.

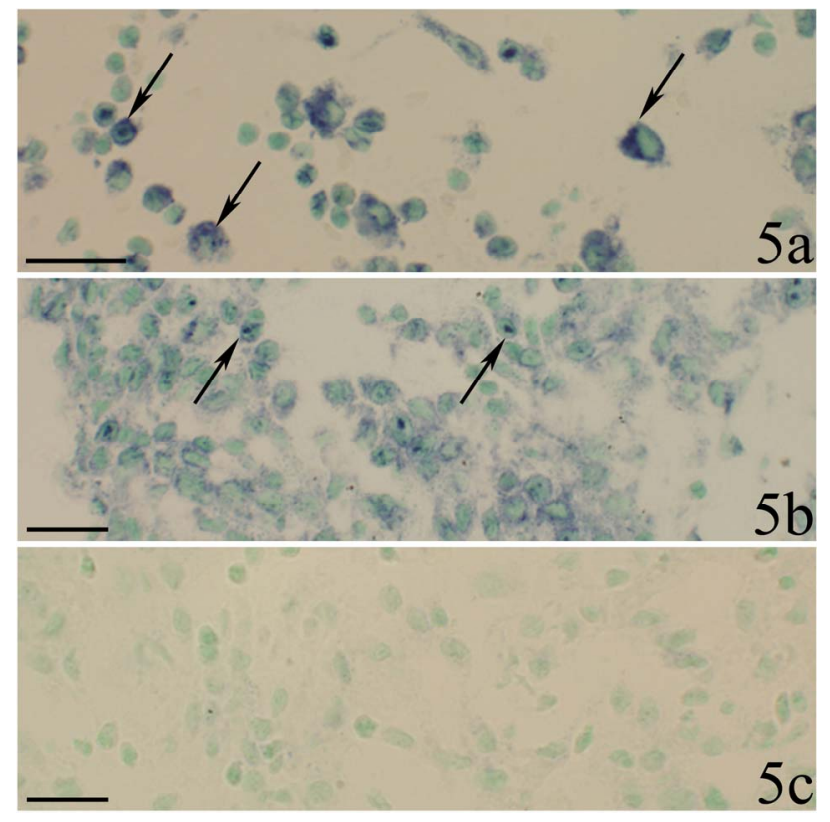

Figure 5. Sections from two animals in the myositis group (SP + $\mathrm{C}+$ Th group). White blood cells are seen to be dispersed in the connective tissue. The sections were processed with TNF-alpha mRNA antisense probe in $\mathrm{a}, \mathrm{b}$ and with sense probe in $\mathrm{c} . \mathrm{b}$ and $\mathrm{c}$ represent parallel sections showing the same region. There are marked TNF-alpha mRNA reactions for a large number of the white blood cells in both a and b (arrows). The cells do not show reactions in c. Scale bars $=25 \mu \mathrm{m}$.

frequently small (c.f. above), but could also be seen to have similar sizes as ordinary appearing muscle fibers. The TNF-alpha mRNA reactive fibers were clearly discriminated from the ordinary muscle fibers already at low magnification (Figure 6a).

The TNF-alpha mRNA expressing muscle fibers showed different appearance (Figures $\mathbf{2 b}$ and 6-8). Some of the reactive fibers exhibited a patchy and granulated reactive pattern (Figures 2b and 7a). Others were to a small extent (Figure 6b) or very markedly (Figures $7 \mathbf{a}$ and 8) infiltrated by white blood cells. The mRNA reactions seen within the latter muscle fibers occurred for the white blood cells, the reactions showing a perinuclear pattern (Figure 8). The reactive muscle fibers that showed a patchy and granulated reaction pattern appeared not to be infiltrated at all by white blood cells (Figures $\mathbf{2 b}$ and 7). Only background reactions were seen for the reactive muscle fibers after staining with sense probe (Figures 6c and $\mathbf{7 b}$ ).

\subsection{Immunohistochemistry}

White blood cells in areas with marked muscle inflammation were found to exhibit TNF-alpha immunoreactions (Figures 9a and $\mathbf{b}$ ). The reactions appeared as intracellular granular reactions. Scanty intracellular granular reactions were also sometimes seen for fibroblasts 


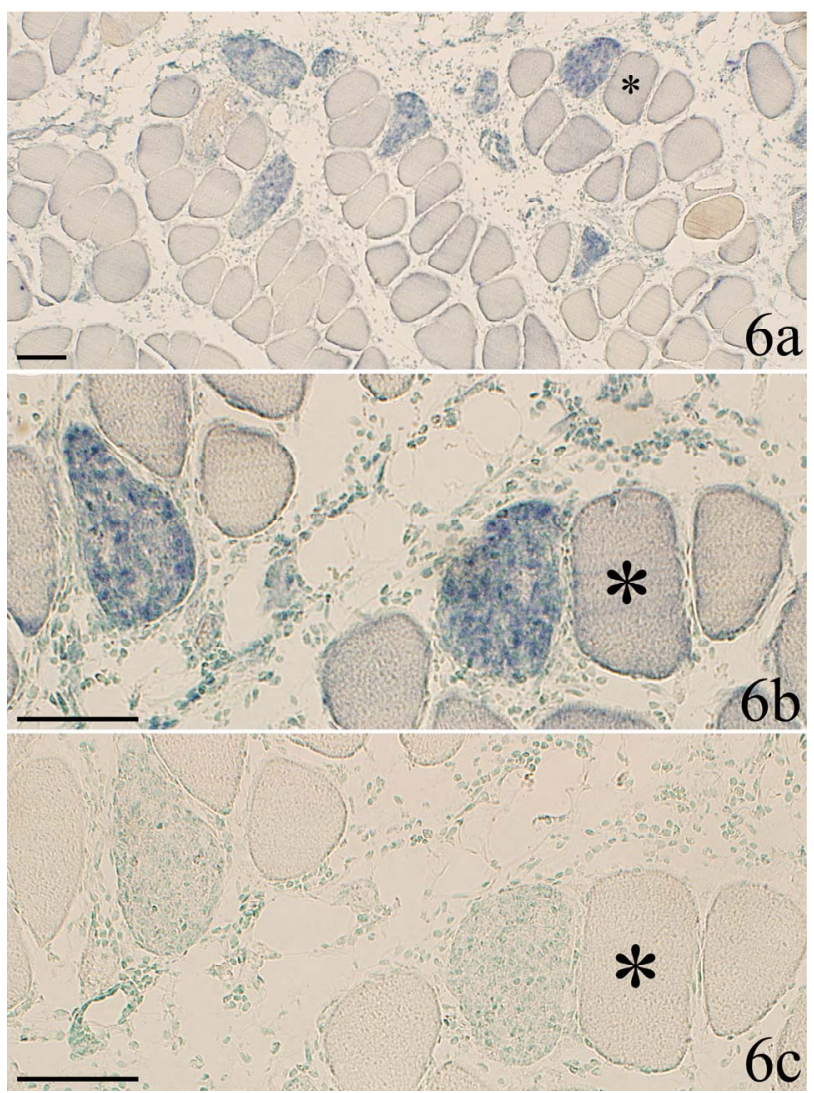

Figure 6. Section a is showing myositis muscle tissue in low magnification after processing with TNF-alpha mRNA antisense probe ( $\mathrm{SP}+\mathrm{C}+\mathrm{Th}$ group). Reactive muscle fibers can be clearly discriminated from muscle fibers that are non-reactive. $b$ and $\mathrm{c}$ are showing the same sample as a but in a higher magnification. $b$ is processed with TNF-alpha mRNA antisense probe and $\mathrm{c}$ with sense probe. Asterix at the same non-reactive muscle fiber. Distinct mRNA reactions are seen in two muscle fibers $b$. There are no reactions in c. Occurrence of cell infiltration of the affected muscle fibers is to some extent seen in c. Scale bars = $100 \mu \mathrm{m}$.

(Figure 9c). No specific reactions were observed with certainty neither for muscle fibers nor for the blood vessel walls. No specific reactions were seen for nerve fascicles as well (not illustrated).

\section{DISCUSSION}

The present study shows that the TNF-alpha system is highly involved in the contralateral side in the early stages of the experimental model of myositis used. There were thus reactions for TNF-alpha both at the mRNA and protein level in the cells of the inflammatory infiltrates and distinct TNF-alpha mRNA reactions were seen in certain of the muscle fibers located in areas with marked inflammation. TNF-alpha mRNA reactions were also to some extent seen for blood vessel walls and fibroblasts. The present findings extend the previous observations of a marked involvement of the TNF-alpha system in the

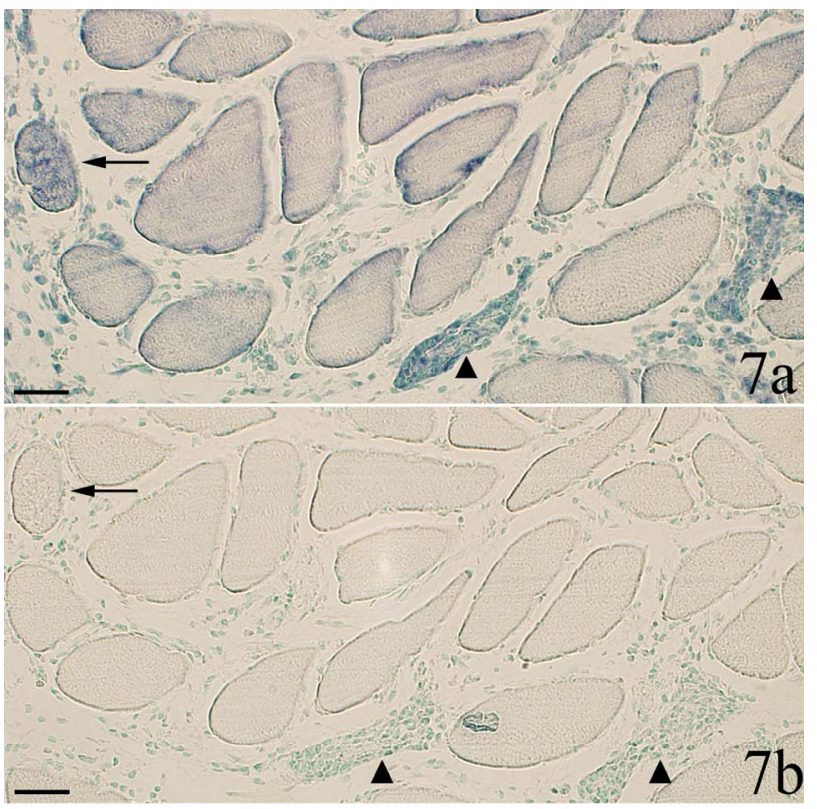

Figure 7. Parallel sections processed with TNF-alpha mRNA antisense and sense probes ( $a$ and $b$ respectively). In $a$, there are three muscle fibers that exhibit TNF-alpha mRNA reactions. These fibers show only unspecific reactions in b. Two of the reactive fibers are infiltrated by white blood cells (triangles) $b$. The muscle fiber to the left (arrow) does not show evidence of white blood cell infiltration in $\mathrm{b}$. Scale bars $=50 \mu \mathrm{m}$.
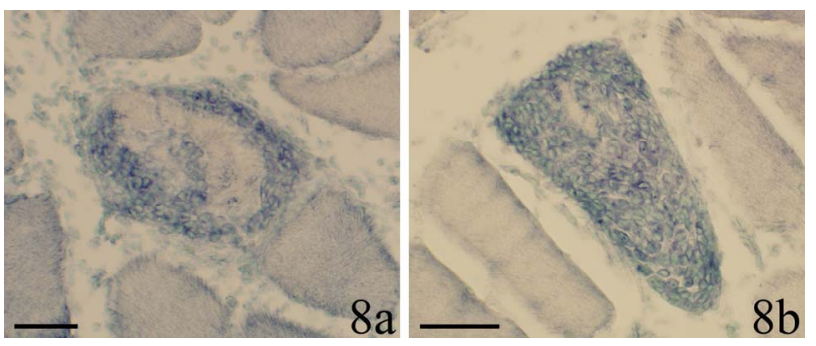

Figure 8. The occurrence of a reaction pattern for TNF-alpha mRNA for necrotic muscle fibers is shown. The fibers are to different extents filled with reactive cells. A perinuclear reaction can be seen. Scale bars $=50 \mu \mathrm{m}$.

exercised side in early stages of myositis [20].

The muscle fibers expressing TNF-alpha mRNA reactions were even at low magnification clearly demarcated from the non-reactive muscle fibers. Different types of TNF-alpha mRNA reactive fibers occurred. One type corresponded to small muscle fibers which were present in areas with loose connective tissue. Another type corresponded to fibers which were completely or to a large extent infiltrated by white blood cells, showing that the fibers were in a necrotic stage. The TNF-alpha mRNA reactions seen in these fibers were actually detected in the white blood cells. Still another type conformed to muscle fibers which were approximately of normal size did not show white blood cell infiltration. These fibers showed another variant of reaction pattern, 


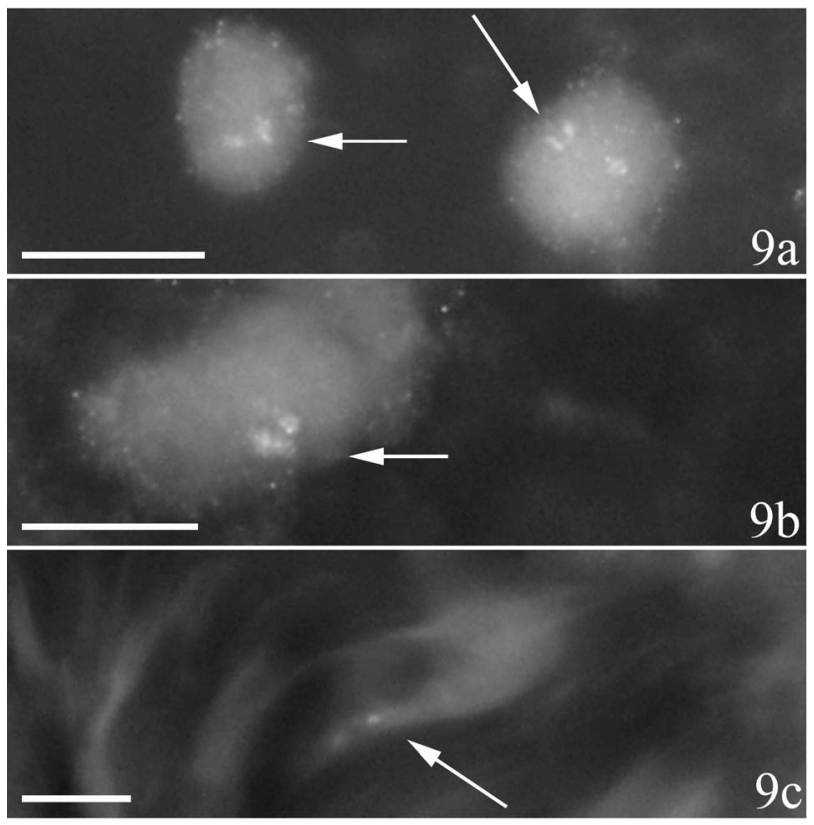

Figure 9. Immunohistochemical staining for TNF-alpha in sections of myositis samples (C group). There are specific TNFalpha reactions within cells of inflammatory infiltrate $\mathrm{a}, \mathrm{b}$ and within a fibroblast $\mathrm{c}$ (arrows). The specific reactions show a granular pattern. Scale bars $=10 \mu \mathrm{m}$.

the TNF-alpha mRNA reaction being rather patchy/ widespread and granular. Similar types of TNF-alpha mRNA reactive fibers were seen in our previous study on the TNF-alpha system in muscle tissue after prolonged overuse (up to 6 weeks) [18]. These reactive fibers, which did not show white blood cell infiltration, were interpreted to be in a regenerative stage, as they were highly desmin reactive [18]. Therefore it seems likely that muscle fibers being in necrotic as well as regenerative stages show TNF-alpha reactions also at an early stage of myositis.

The findings of TNF-alpha mRNA reactions not only for necrotic muscle fibers but also for fibers which presumably are in a regenerative stage indicate that TNFalpha is not only related to destructive and pro-inflammatory effects in situations with myositis. Instead, TNFalpha can be in parallel to its effects for the white blood cells in the necrotic fibers and also be related to recovery functions. Such a function is suggested to be the case for TNF-alpha after traumatic muscle injury, as seen in studies on TNF receptor knockout and TNF-alpha antibodyneutralized mice [6]. It is also previously shown that TNF-alpha administration to myoblast cell cultures does not have catabolic effects [28]. Further studies will reveal the importance of the TNF-alpha system in relation to destructive and regenerative effects for muscle tissue.

Central neuropathic mechanisms may be involved in the bilateral symmetric spread of the myositis/muscle derangement in the present model, including stimulation of afferents unilaterally, secondarily leading to effects contralaterally $[17,21]$. In our previous studies using the model for prolonged experiment periods, we have noted that nerve structures are affected both ipsi- and contralaterally, including showing a changed pattern for the expression of the substance P receptor, the NK-1 receptor [21,29]. A situation with contralateral influence on the innervation after unilateral experiments has also been shown to take place in other situations with unilateral inflammation/insult [30,31]. Primary-afferent activation leading to contralateral activation of homologous afferents has been suggested to take place in the symmetric spread of arthritis [32]. It is hypothesized that the contralateral phenomena in joint affections is an attempt to upregulate protective proinflammatory responses in the preparation for an insult which has already occurred [33]. In a recent study using a burn injury model affecting the hind paw of rats leading to allodynia, it was shown that the allodynia was spread to the contralateral limb, and in this case, microglial activation occurred on both the ipsilateral and contralateral sides of the spinal cord [34].

When discussing the possibility that the muscle overuse leads to neurological influences, secondarily leading to bilateral influences of the muscles, a possibility that TNF-alpha can have effects on the nervous system should be considered. Such a suggestion is favoured by the fact that we in preliminary studies have noted presence of TNF receptors in the nerve fascicles of muscles of rabbits displaying myositis and muscle tissue changes (unpublished observations). A relationship between the TNFalpha system and injury of nerve structures has also been shown for skeletal muscle in studies by Hafer-Macko and colloborators. These authors found that there were elevated TNF-alpha levels in paretic skeletal muscle after stroke [35]. We have previously observed that anti-TNF treatment for patients with rheumatoid arthritis (RA) influences the nervous system in the sense that it leads to a decrease in the levels of the nerve signal substance brain-derived neurotrophic factor in the blood [36]. Experimental studies furthermore suggest that anti-TNF treatment prevents hyperalgesia caused by nerve displacement [37] and that TNF-alpha plays a role in the induction of apoptosis of cells of the dorsal root ganglion of rats [38].

Results of previous studies also suggest that TNF-alpha can be involved in bilateral processes. In recent experimental studies on hindpaws of mice, it was thus observed that TNF-alpha triggered and maintained inflamematory pain bilaterally following unilateral intraplantar injection of TNF-alpha [39]. Milligan and coworkers have furthermore found that unilateral neuritis led to bilateral allodynia, and proinflammatory cytokines were hereby involved [40].

Apart from the possibility that there are neurological 
explanations for the bilateral affection concerning the TNF-alpha system, one should also have in mind that a release of soluble factors from the overused muscle might affect the contralateral unexercised muscle. In future studies using the overuse model, the details in the establishment in the contralateral influences will be explored.

In conclusion, the results of the present study, in parallel with those previously obtained [20], indicate that the TNF-alpha system is of importance early in the inflammatory process and its effect is not only related to an effect in the muscle in the overused/exercised side but also an effect in the muscle in the contralateral nonexercised side. Thus, the contralateral phenomenon related to a TNF-alpha involvement occurs early and does not represent a late phenomenon in response to overuse. It appears as if the TNF-alpha system is related to effects in the necrosis process of muscle fibers as well as in muscle regenerative process. The currently used model can be a useful model in order to further study the involvement of the TNF-alpha system in inflammatory processes in muscle tissue, including studies on the effects of TNFalpha on the nervous system in these conditions. Overall the study gives new proof for a possibility that TNFalpha has an importance in early stages of muscle inflammation and muscle damage, hereby having crossover effects. This is new feature concerning the TNF-alpha system in relation to inflammation.

\section{ETHICS}

The study protocol was approved by the local ethical committee at Umeå University (A 34/07). The approval was obtained before the start of the study. A licensed breeder had bred all animals for the sole purpose of being used in animal experiments. All efforts were made to minimize animal suffering.

\section{ACKNOWLEDGEMENTS}

We thank Ms. Ulla Hedlund, Mr. Adrian Lamoroux, and Ms. Fellon Robson-Long for excellent technical services. We also thank Dr. Clas Backman, Section of Hand Surgery, and Professor Ronny Lorentzon, Section of Orthopaedics, Department of Surgical and Perioperative Science, Umeå University, for co-operation on the animal model.

\section{REFERENCES}

[1] Vassalli, P. (1992) The pathophysiology of tumor necrosis factors. Annual Review of Immunology, 10, 411-452. http://dx.doi.org/10.1146/annurev.iy.10.040192.002211

[2] Reinecker, H.C., Steffen, M., Witthoeft, T., Pflueger, I., Schreiber, S., Macdermott, R.P., et al. (1993) Enhanced secretion of tumour necrosis factor-alpha, IL-6, and IL-1 beta by isolated lamina propria mononuclear cells from patients with ulcerative colitis and Crohn's disease. Clinical \& Experimental Immunology, 94, 174-181. http://dx.doi.org/10.1111/j.1365-2249.1993.tb05997.x

[3] Bischoff, S.C., Lorentz, A., Schwengberg, S., Weier, G., Raab, R. and Manns, M.P. (1999) Mast cells are an important cellular source of tumour necrosis factor alpha in human intestinal tissue. Gut, 44, 643-652. http://dx.doi.org/10.1136/gut.44.5.643

[4] Shibata, H., Abe, Y., Yoshioka, Y., Nomura, T., Sato, M., Kayamuro, H., et al. (2010) Generation of mouse macrophages expressing membrane-bound TNF variants with selectivity for TNFR1 or TNFR2. Cytokine, 50, 75-83. http://dx.doi.org/10.1016/j.cyto.2009.11.022

[5] Reikerås, O. (2010) Immune depression in musculoskeletal trauma. Inflammation Research, 59, 409-414. http://dx.doi.org/10.1007/s00011-010-0167-7

[6] Warren, G.L., Hulderman, T., Jensen, N., Mckinstry, M., Mishra, M., Luster, M.I., et al. (2002) Physiological role of tumor necrosis factor alpha in traumatic muscle injury. FASEB Journal, 16, 1630-1632.

[7] Ihnatko, R. and Kubes, M. (2007) TNF signaling: Early events and phosphorylation. General Physiology and Biophysics, 26, 159-167.

[8] Dalakas, M.C. (2011) Review: An update on inflammatory and autoimmune myopathies. Neuropathology and Applied Neurobiology, 37, 226-242. http://dx.doi.org/10.1111/j.1365-2990.2010.01153.x

[9] Dennett, X. and Fry, H.J. (1988) Overuse syndrome: A muscle biopsy study. Lancet, 1, 905-908. http://dx.doi.org/10.1016/S0140-6736(88)91714-X

[10] Barbe, M.F. and Barr, A.E. (2006) Inflammation and the pathophysiology of work-related musculoskeletal disorders. Brain, Behavior, and Immunity, 20, 423-429. http://dx.doi.org/10.1016/j.bbi.2006.03.001

[11] De Paepe, B., Creus, K.K. and De Bleecker, J.L. (2012) The tumor necrosis factor superfamily of cytokines in the inflammatory myopathies: Potential targets for therapy. Clinical and Developmental Immunology, 2012, 369432. http://dx.doi.org/10.1155/2012/369432

[12] Efthimiou, P. (2006) Tumor necrosis factor-alpha in inflammatory myopathies: Pathophysiology and therapeutic implications. Seminars in Arthritis and Rheumatism, 36, 168-172. http://dx.doi.org/10.1016/j.semarthrit.2006.07.003

[13] Kondo, M., Murakawa, Y., Harashima, N., Kobayashi, S., Yamaguchi, S. and Harada, M. (2009) Roles of proinflammatory cytokines and the Fas/Fas ligand interaction in the pathogenesis of inflammatory myopathies. Immunology, 128, e589-e599. http://dx.doi.org/10.1111/j.1365-2567.2008.03039.x

[14] Tews, D.S. and Goebel, H.H. (1996) Cytokine expression profile in idiopathic inflammatory myopathies. Journal of Neuropathology \& Experimental Neurology, 55, 342-347. http://dx.doi.org/10.1097/00005072-199603000-00009

[15] De Bleecker, J.L., Meire, V.I., Declercq, W. and Van Aken, E.H. (1999) Immunolocalization of tumor necrosis factor-alpha and its receptors in inflammatory myopathies. Neuromuscular Disorders, 9, 239-246. http://dx.doi.org/10.1016/S0960-8966(98)00126-6

[16] Peterson, J.M., Feeback, K.D., Baas, J.H. and Pizza, F.X. 
(2006) Tumor necrosis factor-alpha promotes the accumulation of neutrophils and macrophages in skeletal muscle. Journal of Applied Physiology, 101, 1394-1399. http://dx.doi.org/10.1152/japplphysiol.01453.2005

[17] Song, Y., Forsgren, S., Yu, J., Lorentzon, R. and Stål, P.S. (2012) Effects on contralateral muscles after unilateral electrical muscle stimulation and exercise. PLoS One, 7, e52230. http://dx.doi.org/10.1371/journal.pone.0052230

[18] Renström, L., Song, Y., Stål, P. and Forsgren, S. (2013) TNF-alpha in an overuse muscle model. Relationship to muscle fiber necrosis/regeneration, the NK-1 receptor an occurrence of bilateral involvement. Journal of Clinical \& Cellular Immunology, 4, 1-10.

http://dx.doi.org/10.4172/2155-9899.1000138

[19] Spang, C., Scott, A., Danielson, P., Lorentzon, R. and Forsgren, S. (2012) VGluT2 and NMDAR1 expression in cells in the inflammatory infiltrates in experimentally induced myositis: Evidence of local glutamate signaling suggests autocrine/paracrine effects in an overuse injury model. Inflammation, 35, 39-48.

http://dx.doi.org/10.1007/s10753-010-9287-z

[20] Forsgren, S., Renström, L., Purdam, C. and Gaida, J.E. (2012) TNF-alpha in the locomotor system beyond joints: High degree of involvement in myositis in a rabbit model. International Journal of Rheumatology, 2012, 637452. http://dx.doi.org/10.1155/2012/637452

[21] Song, Y., Stål, P.S., Yu, J. and Forsgren, S. (2013) Marked effects of tachykinin in myositis both in the experimental side and contralaterally: Studies on NK-1 receptor expressions in an animal model. ISRN Inflammation, 2013, 907821. http://dx.doi.org/10.1155/2013/907821

[22] Backman, C., Boquist, L., Fridén, J., Lorentzon, R. and Toolanen, G. (1990) Chronic achilles paratenonitis with tendinosis: An experimental model in the rabbit. Journal of Orthopaedic Research, 8, 541-547. http://dx.doi.org/10.1002/jor.1100080410

[23] Andersson, G., Forsgren, S., Scott, A., Gaida, J.E., Stjernfeldt, J.E., Lorentzon, R., et al. (2011) Tenocyte hypercellularity and vascular proliferation in a rabbit model of tendinopathy: Contralateral effects suggest the involvement of central neuronal mechanisms. British Journal of Sports Medicine, 45, 399-406. http://dx.doi.org/10.1136/bjsm.2009.068122

[24] Panoskaltsis-Mortari, A. and Bucy, R.P. (1995) In situ hybridization with digoxigenin-labeled RNA probes: Facts and artifacts. Biotechniques, 18, 300-307.

[25] Jönsson, M., Norrgård, O. and Forsgren, S. (2007) Presence of a marked nonneuronal cholinergic system in human colon: Study of normal colon and colon in ulcerative colitis. Inflammatory Bowel Disease, 13, 1347-1356. http://dx.doi.org/10.1002/ibd.20224

[26] Bjur, D., Danielson, P., Alfredson, H. and Forsgren, S. (2008) Immunohistochemical and in situ hybridization observations favor a local catecholamine production in the human Achilles tendon. Histology and Histopathology, 23, 197-208.

[27] Rees, G.S., Gee, C.K., Ward, H.L., Ball, C., Tarrant, G.M., Poole, S., et al. (1999) Rat tumour necrosis factor-alpha: Expression in recombinant Pichia pastoris, purification, characterization and development of a novel ELISA. European Cytokine Network, 10, 383-392.

[28] Mullen, B.J., Harris, R.B., Patton, J.S. and Martin, R.J. (1990) Recombinant tumor necrosis factor-alpha chronically administered in rats: Lack of cachectic effect. Proceedings of the Society for Experimental Biology and Medicine, 193, 318-325. http://dx.doi.org/10.3181/00379727-193-43042

[29] Song, Y., Stål, P.S., Yu, J.G. and Forsgren, S. (2013) Bilateral increase in expression and concentration of tachykinin in a unilateral rabbit muscle overuse model that leads to myositis. BMC Musculoskeletal Disorders, 14, 134. http://dx.doi.org/10.1186/1471-2474-14-134

[30] Koltzenburg, M., Wall, P.D. and Mcmahon, S.B. (1999) Does the right side know what the left is doing? Trends in Neuroscience, 22, 122-127. http://dx.doi.org/10.1016/S0166-2236(98)01302-2

[31] Shenker, N., Haigh, R., Roberts, E., Mapp, P., Harris, N. and Blake, D. (2003) A review of contralateral responses to a unilateral inflammatory lesion. Rheumatology $(O x$ ford), 42, 1279-1286.

[32] Donaldson, L.F. (1999) Unilateral arthritis: Contralateral effects. Trends in Neurosciences, 22, 495-496. http://dx.doi.org/10.1016/S0166-2236(99)01481-2

[33] Hood, V.C., Cruwys, S.C., Urban, L. and Kidd, B.L. (2001) The neurogenic contribution to synovial leucocyte infiltration and other outcome measures in a guinea pig model of arthritis. Neuroscience Letters, 299, 201-204. http://dx.doi.org/10.1016/S0304-3940(00)01790-0

[34] Chang, Y.W., Tan, A., Saab, C. and Waxman, S. (2010) Unilateral focal burn injury is followed by long-lasting bilateral allodynia and neuronal hyperexcitability in spinal cord dorsal horn. Journal of Pain, 11, 119-130. http://dx.doi.org/10.1016/j.jpain.2009.06.009

[35] Hafer-Macko, C.E., Yu, S., Ryan, A.S., Ivey, F.M. and Macko, R.F. (2005) Elevated tumor necrosis factor-alpha in skeletal muscle after stroke. Stroke, 36, 2021-2023. http://dx.doi.org/10.1161/01.STR.0000177878.33559.fe

[36] Grimsholm, O., Rantapää-Dahlqvist, S., Dalén, T. and Forsgren, S. (2008) Unexpected finding of a marked nonneuronal cholinergic system in human knee joint synovial tissue. Neuroscience Letters, 442, 128-133. http://dx.doi.org/10.1016/j.neulet.2008.06.082

[37] Murata, Y., Olmarker, K., Takahashi, I., Takahashi, K. and Rydevik, B. (2005) Effects of selective tumor necrosis factor-alpha inhibition to pain-behavioral changes caused by nucleus pulposus-induced damage to the spinal nerve in rats. Neuroscience Letters, 382, 148-152. http://dx.doi.org/10.1016/j.neulet.2005.03.012

[38] Murata, Y., Nannmark, U., Rydevik, B., Takahashi, K. and Olmarker, K. (2008) The role of tumor necrosis factor-alpha in apoptosis of dorsal root ganglion cells induced by herniated nucleus pulposus in rats. Spine (Phila Pa 1976), 33, 155-162.

[39] Russell, F.A., Fernandes, E.S., Courade, J.P., Keeble, J.E. and Brain, S.D. (2009) Tumour necrosis factor alpha mediates transient receptor potential vanilloid 1-dependent bilateral thermal hyperalgesia with distinct peripheral roles of interleukin-1beta, protein kinase $\mathrm{C}$ and cyclooxy- 
genase-2 signalling. Pain, 142, 264-274.

http://dx.doi.org/10.1016/j.pain.2009.01.021

[40] Milligan, E.D., Twining, C., Chacur, M., Biedenkapp, J.,
O'connor, K., Poole, S., et al. (2003) Spinal glia and proinflammatory cytokines mediate mirror-image neuropathic pain in rats. Journal of Neuroscience, 23, 1026-1040. 